\title{
Ring opening metathesis polymerization-derived block copolymers bearing chelating ligands: synthesis, metal immobilization and use in hydroformylation under micellar conditions
}

Gajanan M. Pawar ${ }^{1}$, Jochen Weckesser ${ }^{2}$, Siegfried Blechert ${ }^{*}$ ' and Michael R. Buchmeiser ${ }^{* 1}$

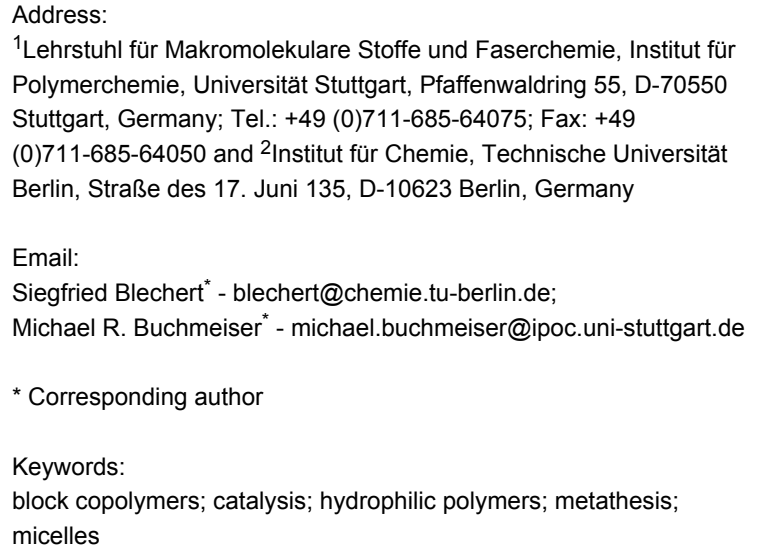

${ }^{1}$ Lehrstuhl für Makromolekulare Stoffe und Faserchemie, Institut für Polymerchemie, Universität Stuttgart, Pfaffenwaldring 55, D-70550 Stuttgart, Germany; Tel.: +49 (0)711-685-64075; Fax: +49 (0)711-685-64050 and ${ }^{2}$ Institut für Chemie, Technische Universität Berlin, Straße des 17. Juni 135, D-10623 Berlin, Germany

Email:

Siegfried Blechert ${ }^{\star}$ - blechert@chemie.tu-berlin.de;

Michael R. Buchmeiser ${ }^{\star}$ - michael.buchmeiser@ipoc.uni-stuttgart.de

* Corresponding author

Keywords:

block copolymers; catalysis; hydrophilic polymers; metathesis;

micelles

Beilstein Journal of Organic Chemistry 2010, 6, No. 28 doi:10.3762/bjoc. 6.28

Received: 11 January 2010

Accepted: 17 March 2010

Published: 23 March 2010

Guest Editor: H. Ritter

C 2010 Pawar et al; licensee Beilstein-Institut.

License and terms: see end of document.

\begin{abstract}
Norborn-5-ene-( $N, N$-dipyrid-2-yl)carbamide (M1) was copolymerized with exo,exo-[2-(3-ethoxycarbonyl-7-oxabicyclo[2.2.1]hept5-en-2-carbonyloxy)ethyl]trimethylammonium iodide (M2) using the Schrock catalyst $\mathrm{Mo}_{\left(\mathrm{N}-2,6-\mathrm{Me}_{2}-\right.}$ $\left.\mathrm{C}_{6} \mathrm{H}_{3}\right)\left(\mathrm{CHCMe}_{2} \mathrm{Ph}\right)\left(\mathrm{OCMe}\left(\mathrm{CF}_{3}\right)_{2}\right)_{2}$ [Mo] to yield poly(M1-b-M2). In water, poly(M1- $b$-M2) forms micelles with a critical micelle-forming concentration $(\mathrm{cmc})$ of $2.8 \times 10^{-6} \mathrm{~mol} \mathrm{~L}^{-1}$; Reaction of poly $(\mathbf{M 1}-b-\mathbf{M} 2)$ with $[\mathrm{Rh}(\mathrm{COD}) \mathrm{Cl}]_{2}(\mathrm{COD}=$ cycloocta1,5-diene) yields the $\mathrm{Rh}(\mathrm{I})$-loaded block copolymer poly(M1- $b$-M2)-Rh containing $18 \mathrm{mg}$ of $\mathrm{Rh}(\mathrm{I}) / \mathrm{g}$ of block copolymer with a $\mathrm{cmc}$ of $2.2 \times 10^{-6} \mathrm{~mol} \mathrm{~L}^{-1}$. The Rh-loaded polymer was used for the hydroformylation of 1-octene under micellar conditions. The data obtained were compared to those obtained with a monomeric analogue, i.e. $\mathrm{CH}_{3} \mathrm{CON}(\mathrm{Py}){ }_{2} \mathrm{RhCl}(\mathrm{COD})(\mathrm{C1}$, $\mathrm{Py}=2$-pyridyl). Using the polymer-supported catalyst under micellar conditions, a significant increase in selectivity, i.e. an increase in the $n: i s o$ ratio was accomplished, which could be further enhanced by the addition of excess ligand, e.g., triphenylphosphite. Special features of the micellar catalytic set up are discussed.
\end{abstract}




\section{Introduction}

Catalysts bound to amphiphilic block copolymers find increasing use in micellar catalysis since they combine the advantages of both homogeneous and heterogeneous catalysis in one system. Thus, with catalysts permanently linked to the block copolymer, metal leaching is substantially reduced and allows for the separation/reuse of the catalyst [1-7]. In cases where reactions are run in polar media, the catalyst is best located inside the hydrophobic micellar core, where, upon micelle formation of the functionalized block copolymer, the monomer will also accumulate. This leads to high educt concentrations at the polymer-bound catalyst, often resulting in high reaction rates in water [8]. We recently reported on the synthesis of $\mathrm{Rh}^{\mathrm{I}}$ and $\mathrm{Ir}^{\mathrm{I}}$ complexes of $N, N$-dipyrid-2-ylacetamide and their use in hydroformylation reactions [9]. Here, we report on the immobilization of a Rh- $N, N$-dipyrid-2-ylacetamide-based catalyst on a soluble, amphiphilic, ring-opening metathesis polymerization- (ROMP) derived block copolymer and its use in hydroformylation [10] under micellar conditions [3,5,11]. This medium activity and selectivity dipyrid-2-ylamide-based $\mathrm{Rh}(\mathrm{I})$-catalyst was chosen in order to identify the potential advantages of a micellar setup.

\section{Results and Discussion Synthesis of monomers}

The synthesis of norborn-5-ene-( $N, N$-dipyrid-2-yl)carbamide (M1) was accomplished via reaction of norborn-5-ene-2ylcarboxylic acid chloride with dipyrid-2-ylamine in the presence of triethylamine as described elsewhere [9]. exo,exo-[2-(3Ethoxycarbonyl-7-oxabicyclo[2.2.1] hept-5-ene-2carbonyloxy)ethyl]trimethylammonium iodide (M2) was prepared in a four-step procedure (Scheme 1). It entailed the reaction of 7-oxanorborn-5-ene-2,3-dicarboxylic anhydride with 2-( $N, N$-dimethylamino)ethan-1-ol, conversion of the free carboxylic acid $\mathbf{1}$ into the corresponding acid chloride with $\mathrm{SOCl}_{2}$ and reaction of the acid chloride with dry ethanol to form the diester 2. Finally, compound $\mathbf{2}$ was converted into $\mathbf{M} 2$ via quaternization of the tertiary amine with methyl iodide.

\section{Synthesis of homo- and block copolymers via ROMP [12,13]}

ROMP has already been used for the synthesis of micelleforming block copolymers [14], however, the one used in this study, i.e. poly(M1-b-M2), required special attention. Though M1 contains a chelating ligand and can be polymerized by both Schrock and Grubbs-type initiators [15-18]. M2 is particularly problematic since it contains a quaternary ammonium moiety and has the ability to alkylate the phosphane or pyridine ligands of $1^{\text {st }}-, 2^{\text {nd }}$-, and $3^{\text {rd }}$-generation Grubbs-type initiators. We therefore chose one of the most active Schrock-type initiator [19-21] for polymerization, i.e. $\mathrm{Mo}\left(\mathrm{N}-2,6-\mathrm{Me}_{2}-\right.$ $\left.\mathrm{C}_{6} \mathrm{H}_{3}\right)\left[\mathrm{CHC}\left(\mathrm{CH}_{3}\right)_{2} \mathrm{Ph}\right]\left[\mathrm{OCMe}\left(\mathrm{CF}_{3}\right)_{2}\right]_{2}$ ([Mo]) [22].

Both the homopolymerization of M1 and M2 by the action of [Mo] proceeded smoothly at room temperature. Conversion of monomer M1 reached 100\% after $10 \mathrm{~min}$ (Figure S1, Supporting Information File 1). The corresponding block copolymer poly(M1- $b$-M2) $\left(M_{\mathrm{n}}=44100 \mathrm{~g} \mathrm{~mol}^{-1}\right.$, PDI $=1.38$, Scheme 2) was prepared in $76 \%$ isolated yield by starting the polymerization with M1 and adding M2 after $20 \mathrm{~min}$. The GPC-traces of the first and second block are shown in Figure S2 (Supporting Information File 1) and indicate that the diblock copolymer formed quantitatively. From GPC analysis, degrees of polymerization of 63 and 61 were found for the poly(M1) and the poly(M2) block, respectively.

\section{Critical micelle forming concentrations, metal loading of poly(M1-co-M2)}

The cmc of poly(M1-co-M2) was determined by fluorescence spectroscopy [23]. For measurements in water, 6- $p$-toluidene-2naphthylsulfonic acid $\left(10^{-6} \mathrm{~mol} / \mathrm{L}\right)$ was used as the fluorescence probe. A $\mathrm{cmc}_{\text {water }}$ for poly(M1- $b$-M2) of $2.8 \times$ $10^{-6} \mathrm{~mol} \mathrm{~L}^{-1}$ was determined (Figure S3, Supporting Information File 1). Next, poly(M1- $b$-M2) was loaded with $\mathrm{Rh}(\mathrm{I})$ via reaction of poly(M1- $b$-M2) with $[\mathrm{RhCl}(\mathrm{COD})]_{2}(\mathrm{COD}=$ cycloocta-1,5-diene) to yield poly(M1-b-M2)-Rh (Scheme 2).

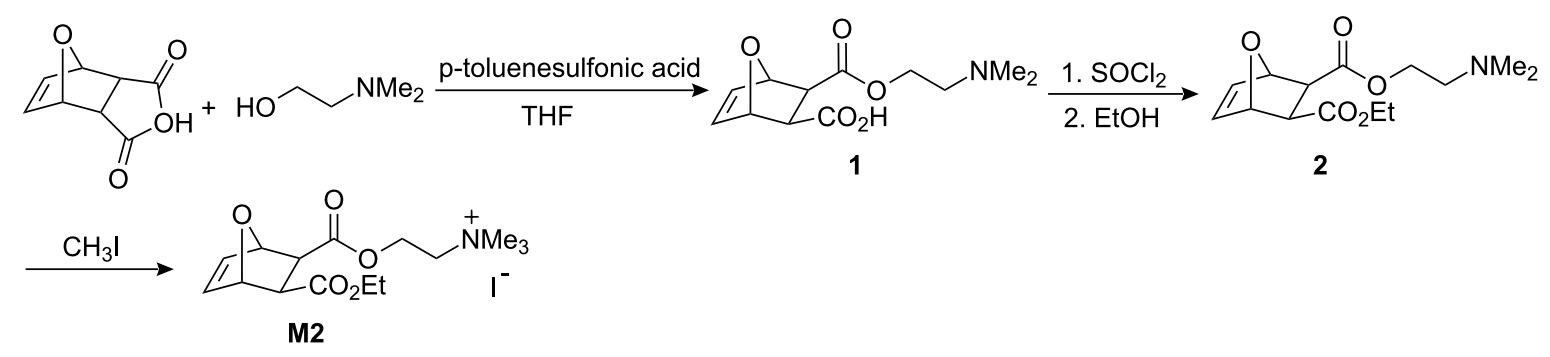




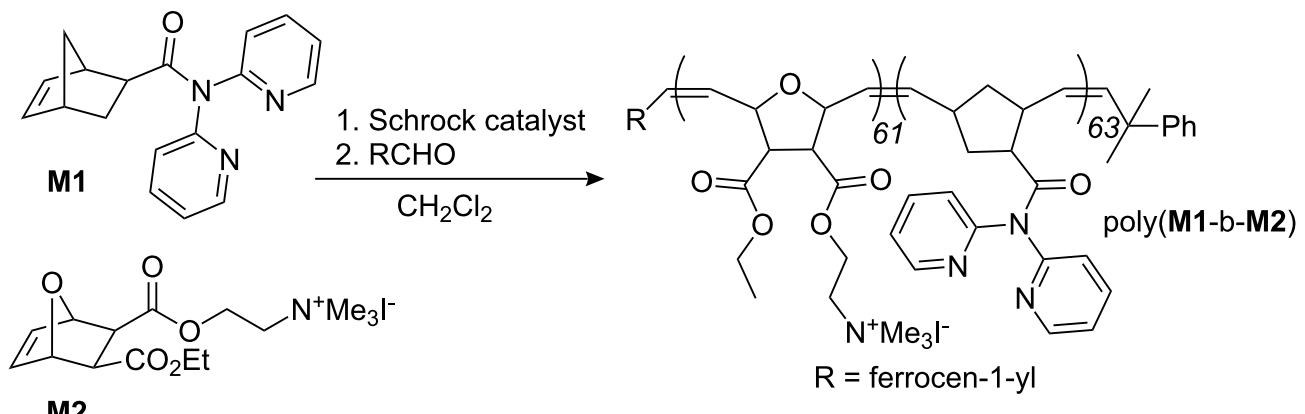

M2

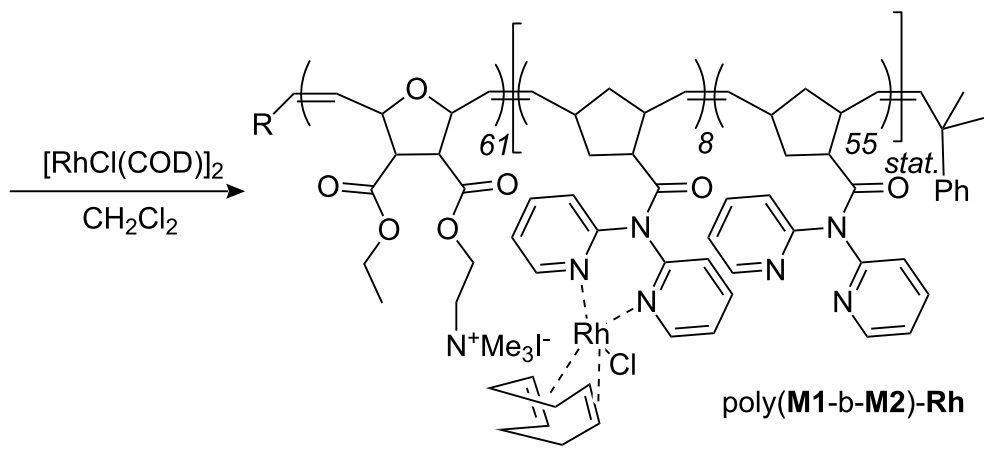

Scheme 2: Synthesis of poly(M1-b-M2) and of the micellar catalyst poly(M1-b-M2)-Rh.

A metal loading of $18 \mathrm{mg} \mathrm{Rh} / \mathrm{g}$ polymer was achieved, which corresponds to $12 \%$ of the theoretical loading (assuming the formation of a mono-dipyridyl-Rh(I) complex as observed for M1) [9]. Consequently, almost $90 \%$ of the dipyrid-2-ylamide ligands were not involved in complex formation, which is of importance for the catalytic behavior of the supported catalyst and for metal leaching. Poly(M1- $b$-M2)-Rh was again subject to cmc measurements. A value of $2.2 \times 10^{-6} \mathrm{~mol} \mathrm{~L}^{-1}$ was found, indicating that the loading with $\mathrm{Rh}(\mathrm{I})$ hardly changes the cmc value (Figure S4, Supporting Information File 1).

\section{Hydroformylation under micellar conditions}

Generally, micellar catalysis [3,5,24-28] and in particular micellar set-ups, where catalysts covalently bound to amphiphilic polymers are used [2,4,29-33], have been reported to present suitable catalysts for numerous catalytic reactions. The hydroformylation under micellar conditions using catalysts bound to amphiphilic block copolymers was first reported by Nuyken et al. [34]. Using a poly(2-oxazoline)-based amphiphilic copolymer and a $\operatorname{RhBr}(1,3$-dialkylimidazol-2ylidene-based catalyst, selectivities (n:iso) of $\sim 3$ at $40 \%$ conversion and an activity $\left(\mathrm{TOF}_{0}\right)$ of $1630 \mathrm{~h}^{-1}$ in the hydroformylation of 1-octene was observed [35]. Here, we used poly(M1- $b$ M2)-Rh for the hydroformylation of 1-octene in water. For purposes of comparison, the results obtained were compared to those previously obtained with the homogeneous analogue $\mathrm{CH}_{3} \mathrm{CON}(\mathrm{Py})_{2} \mathrm{RhCl}(\mathrm{COD})$ (C1) [9].
As already described [9], the dipyridylamide-based Rh-catalyst $\mathbf{C 1}$ is a very fast isomerization catalyst. Consequently, considerable amounts of iso-octanes and a low $n$ :iso ratio of 0.9 was reported for this catalyst (Table 1 , entry 3 ).

\begin{tabular}{|c|c|c|c|c|c|}
\hline No. & Catalyst & Solvent & TON $^{\mathrm{C}}$ & TOF $_{0}$ & n:iso \\
\hline 1 & poly(M1-b-M2)-Rh & water & 3800 & 1200 & 1.5 \\
\hline 2 & poly(M1-b-M2)-Rh ${ }^{b}$ & water & 4400 & 1200 & 2.3 \\
\hline 3 & C1 & toluene & 4500 & 2700 & 0.9 \\
\hline 4 & $c 1^{b}$ & toluene & 4700 & 1600 & 1.6 \\
\hline
\end{tabular}

${ }^{\mathrm{a}}$ catalyst:substrate ratio $=1: 5000, t=4 \mathrm{~h}, T=70^{\circ} \mathrm{C}$.

btriphenylphosphite:substrate $=10: 5000$.

cbased on the aldehydes formed.

When poly(M1-co-M2)-Rh was used in water, a turn-over number (TON) of 4700 and an initial turn-over frequency $\left(\mathrm{TOF}_{0}\right)$ of $1200 \mathrm{~h}^{-1}$ was observed. The $n$ :iso ratio, however, was higher than the one obtained with $\mathbf{C 1}$ in toluene, i.e. 1.5 vs. 0.9 for C1 (Table 1, entry 1, Figure S5, Supporting Information File 1). At $40 \%$ conversion, an $n$ :iso ratio of 1.6 (Figure S6, Supporting Information File 1) was found. A representative product distribution obtained with poly(M1-co-M2)-Rh is shown in Figure 1. This enhanced selectivity is attributed to the presence of a comparably large percentage $(88 \%)$ of free 
dipyrid-2-ylamide ligands as well as to the high concentration of educts within the micelle. Both apparently suppress $\beta$-elimination in the alkyl-metal species. Consequently, a further addition of free ligand (e.g., triphenylphosphite), which is known to favor the formation of $n$-aldehydes in homogenous catalysis $[10,36]$, the $n$ :iso value could be further increased to 2.3 (Table 1, entry 2, Figure 2) and to 2.5 at $40 \%$ conversion, respectively (Figure S6, Supporting Information File 1). As a matter of fact, neither ethylheptanal or propylhexanal nor the parent 3- and 4-octenes was observed in this experiment.

By contrast, the $n$ :iso value increased only to 1.6 with $\mathbf{C 1}$ in toluene upon addition of excess ligand (Figure S7, Supporting Information File 1), clearly demonstrating the effect of the micelle, where both the reactants and the additional ligand (i.e. triphenylphosphite) accumulate. Finally and importantly, the leaching of Rh from poly(M1-co-M2)-Rh into the products was very low, resulting in metal contaminations of around $9 \mathrm{ppm}$. Again, the large excess of free dipyrid-2-ylamine ligand is thought to be responsible for this finding. Moreover, the polymer-bound catalyst can be recycled by extracting the products with diethyl ether and reused with only a minor change in activity. Thus, the TONs obtained were 4300 and 3900 for the first and second run.

\section{Conclusion}

An amphiphilic block copolymer bearing a chelating $N, N$ dipyrid-2-ylamide-based ligand was prepared via ROMP using a Mo-based Schrock initiator. Loading with Rh(I) yielded a polymer-bound catalyst that was used for the hydroformylation
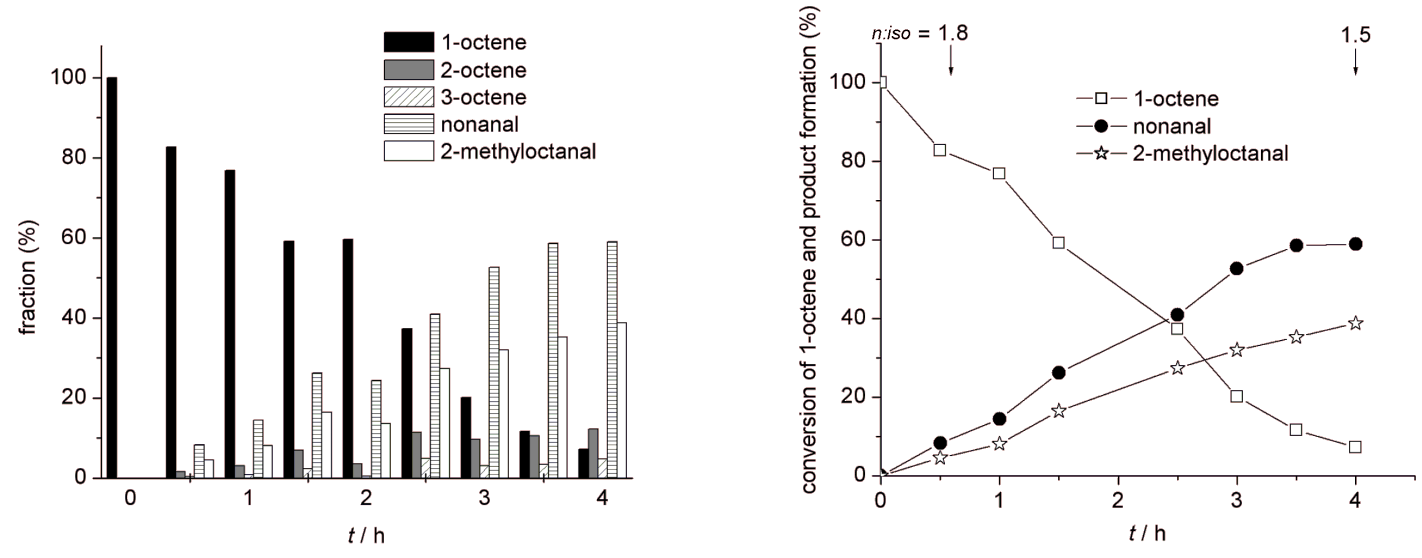

Figure 1: Conversion (\%) of 1-octene, product formation, product distribution, as well as time dependant $n$ :iso ratio in the hydroformylation of 1 -octene in water in the presence of poly(M1-b-M2)-Rh.
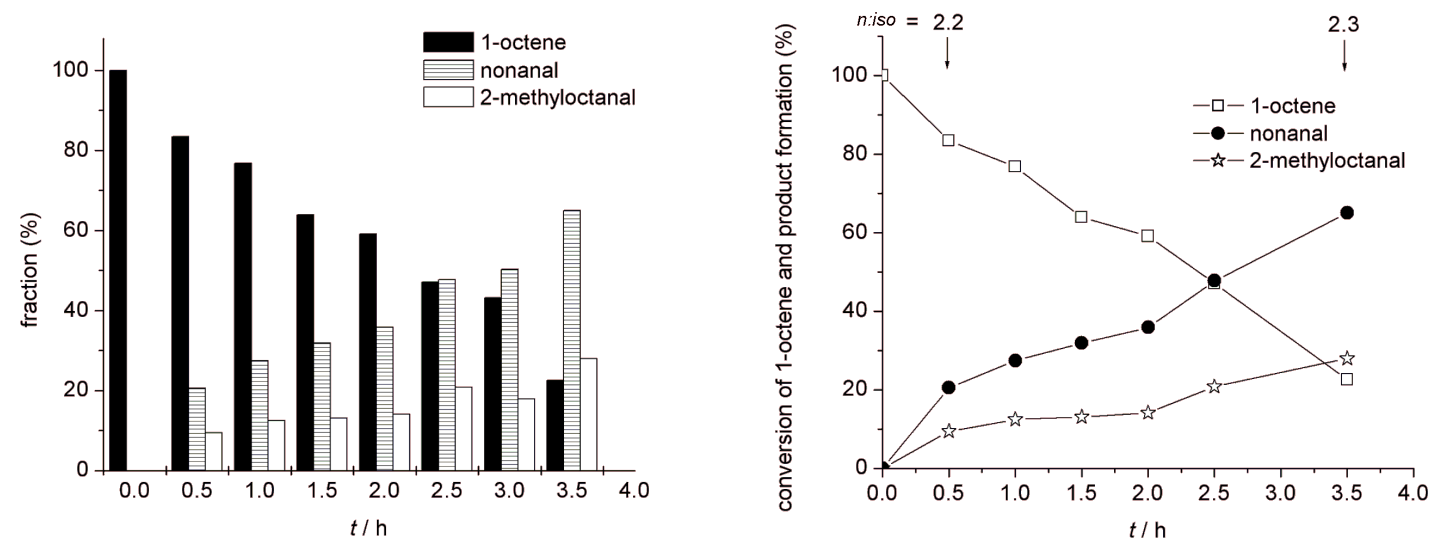

Figure 2: Conversion of 1-octene, product formation and product distribution in the hydroformylation in water in the presence of poly(M1-b-M2)-Rh and triphenylphosphite. 
of 1-octene. From the hydroformylation data obtained with the polymer-bound catalyst as well as with the model catalyst, it becomes clear that the use of a micellar catalyst favors the formation of the $n$-aldehyde by suppressing the isomerization propensity of a catalyst. Apparently, the higher concentration of the starting alkene inside the micelle effectively prevents $\beta$-elimination, an effect that can be further enhanced by adding free ligand that again accumulates inside the micelle. Further advantages in favor of a micellar setup are the low metal contamination of the products as well as the possibility of reuse.

\section{Experimental}

All manipulations were performed under a $\mathrm{N}_{2}$ atmosphere in a glove box (LabMaster 130, MBraun, Garching, Germany) or by standard Schlenk techniques unless stated otherwise. Purchased starting materials were used without any further purification. Pentane, diethyl ether, toluene, $\mathrm{CH}_{2} \mathrm{Cl}_{2}$ and tetrahydrofuran (THF) were dried using a solvent purification system (SPS, MBraun). Benzene, $n$-hexane and dimethoxyethane (DME) were dried and distilled from sodium/benzophenone ketyl under argon. NMR spectra were recorded at room temperature on a Bruker AM 400 (400 MHz for proton and 100.6 MHz for carbon) and on a Bruker Avence $600 \mathrm{II}^{+}(600.25 \mathrm{MHz}$ for proton and $150.93 \mathrm{MHz}$ for carbon) spectrometer, respectively, unless specified otherwise. Proton and carbon spectra were referenced to the internal solvent resonance and are reported in ppm. Molecular weights and polydispersity indices (PDIs) of the polymers were determined by GPC at $40{ }^{\circ} \mathrm{C}$ on Waters columns (Styragel HR 4 DMF, $4.6 \times 300 \mathrm{~mm}$ ) in DMF vs. poly(styrene) using a Waters 717 plus autosampler and a Waters 2414 refractive index detector. For calibration, poly(styrene) samples (PDI $<1.02$ ) with molecular weights within the range $162<M_{\mathrm{n}}<5,500,000 \mathrm{~g} / \mathrm{mol}$ were used. The flow rate was $1.0 \mathrm{~mL} / \mathrm{min}$. Fluorescence testing was performed using a Perkin-Elmer luminescence spectrometer LS50B. IR spectra were recorded on a Bruker Vector 22 using ATR technology. Elemental analysis was carried out on Elementar Varia El (Analytik Jena). GC-MS investigations were carried out on a Shimadzu GCMS-QP5050 with an AOC-20i Autosampler using a SPB fused silica (Rxi-5MS) column $(30 \mathrm{~m} \times 0.25 \mathrm{~mm} \times$ $0.25 \mu \mathrm{m}$ film thickness, $60.6 \mathrm{kPa}$, temperature program: $70^{\circ} \mathrm{C}-$ $\left.300{ }^{\circ} \mathrm{C}, 25 \mathrm{~min}\right)$. The Schrock initiator $\mathrm{Mo}\left(\mathrm{N}-2,6-\mathrm{Me}_{2}-\right.$ $\left.\mathrm{C}_{6} \mathrm{H}_{3}\right)\left[\mathrm{CHC}\left(\mathrm{CH}_{3}\right)_{2} \mathrm{Ph}\right]\left[\mathrm{OCMe}\left(\mathrm{CF}_{3}\right)_{2}\right]_{2}$ [Mo] [22], N,Ndipyridyl-endo-norborn-5-ene-2-carbamide (M1) $[9,37]$ and $N$-acetyl- $N, N$-dipyrid-2-yl (cyclooctadiene) rhodium chloride (C1) [9] were synthesized according to the literature.

exo,exo-[2-(3-Ethoxycarbonyl-7-oxabicyclo[2.2.1]hept-5-en2-carbonyloxy)ethyl] trimethylammonium iodide (M2) exo,exo-7-Oxabicyclo[2.2.1]hept-5-ene-2,3-dicarboxylic acid mono(2-dimethylaminoethyl) ester (1): exo-3,6-Epoxy- 1,2,3,6-tetrahydrophtalic anhydride $(10.0 \mathrm{~g}, 60.0 \mathrm{mmol})$, 2-dimethylaminoethanol (6.3 mL, $62.0 \mathrm{mmol}, 1.03 \mathrm{equiv})$ and p-toluenesulfonic acid (590 mg, $3.1 \mathrm{mmol}, 5 \mathrm{~mol} \%$ ) were dissolved in $120 \mathrm{~mL}$ of THF and stirred at room temperature for $8 \mathrm{~h}$. The white precipitate was filtered, washed with diethyl ether and dried to afford a white solid; yield: $13.8 \mathrm{~g}(90.0 \%) .{ }^{1} \mathrm{H}$ NMR $\left(\mathrm{CDCl}_{3}\right): \delta 2.70(\mathrm{~s}, 6 \mathrm{H}), 2.78-2.81(\mathrm{~m}, 2 \mathrm{H}), 3.01$ (ddd, $\left.1 \mathrm{H},{ }^{2} J=13.7 \mathrm{~Hz}, J=6.8 \mathrm{~Hz}, J=2.8 \mathrm{~Hz}\right), 3.12(\mathrm{ddd}, 1 \mathrm{H}$, $\left.{ }^{2} J=13.7 \mathrm{~Hz}, J=7.3 \mathrm{~Hz}, J=2.8 \mathrm{~Hz}\right), 4.37\left(\mathrm{ddd}, 1 \mathrm{H},{ }^{2} J=13.3\right.$ $\mathrm{Hz}, J=7.3 \mathrm{~Hz}, J=2.8 \mathrm{~Hz}), 4.51\left(\mathrm{ddd}, 1 \mathrm{H},{ }^{2} J=13.3 \mathrm{~Hz}, J=6.8\right.$ $\mathrm{Hz}, J=2.8 \mathrm{~Hz}), 5.24(\mathrm{~s} \mathrm{br}, 2 \mathrm{H}), 6.37$ (dd, 1H, $J=5.7 \mathrm{~Hz}, J=$ $1.6 \mathrm{~Hz}), 6.47(\mathrm{dd}, 1 \mathrm{H}, J=5.7 \mathrm{~Hz}, J=1.6 \mathrm{~Hz})$.

exo,exo-7-Oxabicyclo[2.2.1]hept-5-ene-2,3-dicarboxylic acid 2-(2-dimethylaminoethyl) ester 3-ethyl ester (2): 1 (1.0 g, $3.9 \mathrm{mmol})$ was dissolved in $20 \mathrm{~mL}$ of EtOH $(c=0.2 \mathrm{M})$. $\mathrm{SOCl}_{2}$ $(0.4 \mathrm{~mL}, 5.9 \mathrm{mmol}, 1.5$ equiv) was added dropwise at room temperature and the reaction mixture was stirred at room temperature for $8 \mathrm{~h}$. The solvent was removed in vacuo, the green residue dissolved in $25 \mathrm{~mL}$ of $\mathrm{CH}_{2} \mathrm{Cl}_{2}$ and washed with $10 \mathrm{~mL}$ of sat. $\mathrm{NaHCO}_{3}$ solution. The aqueous phase was extracted with $\mathrm{CH}_{2} \mathrm{Cl}_{2}(3 \times 10 \mathrm{~mL})$ and the combined organic layers were dried over $\mathrm{MgSO}_{4}$. Finally, the solvent was removed under reduced pressure to afford a yellow oil; yield: $695 \mathrm{mg}(60 \%)$. ${ }^{1} \mathrm{H}$ NMR $\left(\mathrm{CDCl}_{3}\right): \delta 1.29(\mathrm{t}, 3 \mathrm{H}, J=7.2 \mathrm{~Hz}), 2.30(\mathrm{~s}, 6 \mathrm{H}), 2.59$ $(\mathrm{t}, 2 \mathrm{H}, J=5.8 \mathrm{~Hz}), 2.81(\mathrm{~d}, 1 \mathrm{H}, J=9.0 \mathrm{~Hz}), 2.88(\mathrm{~d}, 1 \mathrm{H}, J=9.0$ $\mathrm{Hz}), 4.16-4.21(\mathrm{~m}, 3 \mathrm{H}), 4.23-4.28(\mathrm{~m}, 1 \mathrm{H}), 5.28(\mathrm{~s}, 1 \mathrm{H}), 5.29$ (s, 1H), 6.47 (s, 2H).

exo,exo-[2-(3-Ethoxycarbonyl-7-oxabicyclo[2.2.1] hept-5ene-2-carbonyloxy)ethyl]trimethylammonium iodide (M2): 2 (659 mg, $2.3 \mathrm{mmol}$ ) was dissolved in $2 \mathrm{~mL}$ of $\mathrm{CH}_{3} \mathrm{I}$ at $0{ }^{\circ} \mathrm{C}$. The reaction mixture was stirred for $30 \mathrm{~min}$ at $0{ }^{\circ} \mathrm{C}$ and for $8 \mathrm{~h}$ at room temperature. The resulting yellow precipitate was isolated by filtration, dried and recrystallized from boiling ethanol. The crude product was dissolved in $\mathrm{CH}_{2} \mathrm{Cl}_{2}$ and precipitated with hexane to afford a white solid; yield: $875 \mathrm{mg}(88 \%) .{ }^{1} \mathrm{H}$ NMR $\left(\mathrm{CDCl}_{3}\right): \delta 1.30(\mathrm{t}, 3 \mathrm{H}, J=7.2 \mathrm{~Hz}), 2.86\left(\mathrm{~d}, 1 \mathrm{H},{ }^{2} J=9.0\right.$ $\mathrm{Hz}), 2.94\left(\mathrm{~d}, 1 \mathrm{H},{ }^{2} J=9.0 \mathrm{~Hz}\right), 3.54(\mathrm{~s}, 9 \mathrm{H}), 4.16(\mathrm{q}, 2 \mathrm{H}, J=7.2$ $\mathrm{Hz}), 4.10-4.23(\mathrm{~m}, 2 \mathrm{H}), 4.56\left(\mathrm{dd}, 1 \mathrm{H},{ }^{2} J=14.0 \mathrm{~Hz}, J=5.1\right.$ $\mathrm{Hz}), 4.74\left(\mathrm{dd}, 1 \mathrm{H},{ }^{2} J=14.0 \mathrm{~Hz}, J=6.9 \mathrm{~Hz}\right), 5.15$ (s br, $\left.1 \mathrm{H}\right)$, $5.43(\mathrm{~s} \mathrm{br}, 1 \mathrm{H}), 6.48(\mathrm{dd}, 1 \mathrm{H}, J=5.8 \mathrm{~Hz}, \mathrm{~J}=1.4 \mathrm{~Hz}), 6.50$ (dd, $1 \mathrm{H}, J=5.8 \mathrm{~Hz}, J=1.6 \mathrm{~Hz}) .{ }^{13} \mathrm{C} \mathrm{NMR}\left(\mathrm{CDCl}_{3}, 100 \mathrm{MHz}\right): \delta$ $14.24\left(\mathrm{CH}_{3}\right), 46.77(\mathrm{CH}), 47.91(\mathrm{CH}), 54.88\left(\mathrm{CH}_{3}\right), 58.65$ $\left(\mathrm{CH}_{2}\right), 61.69\left(\mathrm{CH}_{2}\right), 64.75\left(\mathrm{CH}_{2}\right), 80.10(\mathrm{CH}), 80.87(\mathrm{CH})$, $136.52(\mathrm{CH}), 136.76(\mathrm{CH}), 171.19\left(\mathrm{C}_{\mathrm{q}}\right), 172.00\left(\mathrm{C}_{\mathrm{q}}\right) . \mathrm{IR}(\mathrm{ATR})$ $v\left(\mathrm{~cm}^{-1}\right)=3433(\mathrm{w}), 3002(\mathrm{w}), 2977(\mathrm{w}), 1732(\mathrm{ss}), 1190(\mathrm{ss})$, 1157 (ss) 913 (s), 887 (s). Elemental analysis: calcd. for $\mathrm{C}_{15} \mathrm{H}_{24} \mathrm{INO}_{5}$ : C, 42.36; H, 5.69; N, 3.29; found: C, 42.25; $\mathrm{H}$, $5.71 ; \mathrm{N}, 3.29$. 
Homopolymerization of M1: M1 (100 mg, $0.339 \mathrm{mmol})$ was dissolved in $5 \mathrm{~mL}$ of $\mathrm{CH}_{2} \mathrm{Cl}_{2}$ and treated with a solution of [Mo] $(2.4 \mathrm{mg}, 0.0034 \mathrm{mmol})$ in $1 \mathrm{~mL}$ of $\mathrm{CH}_{2} \mathrm{Cl}_{2}$. The yellow reaction mixture was stirred for $2 \mathrm{~h}$ at room temperature. A solution of ferrocene carboxaldehyde (10-fold excess based on initiator) in $\mathrm{CH}_{2} \mathrm{Cl}_{2}$ was added and the mixture was stirred for $1 \mathrm{~h}$ at room temperature. The polymer was precipitated by addition of pentane, filtered off, thoroughly washed with pentane and dried; yield: $85 \mathrm{mg}$ (85\%). Poly(M1): $M_{\mathrm{n}(\mathrm{calc})}=29400 \mathrm{~g}$ $\mathrm{mol}^{-1}, M_{\mathrm{n}(\text { found })}=37900 \mathrm{~g} \mathrm{~mol}^{-1} ; \mathrm{PDI}=1.21 .{ }^{1} \mathrm{H} \mathrm{NMR}$ $\left(\mathrm{CDCl}_{3}\right): \delta 8.39$ (broad d, 2H Py), 7.72 (broad d, 2H Py), 7.34 (broad d, 2H Py), 7.14 (broad d, 2H Py), 5.72-5.43 (broad t, 2H $-\mathrm{C} \underline{\mathrm{H}}=\mathrm{C} \underline{\mathrm{H}}-$ ), 3.12 (broad s, 1H NBE), 2.89-2.23 (broad d, 2H $\mathrm{NBE}$ ), 2.20-1.20 (broad d, 4H NBE). ${ }^{13} \mathrm{C} \mathrm{NMR}\left(\mathrm{CDCl}_{3}\right): \delta$ $175.0(\mathrm{C}=\mathrm{O}), 154.8,148.9,137.8,134.6$ and 130.2 (all Py), 122.6 and $121.9(-\underline{\mathrm{CH}}=\underline{\mathrm{CH}}-), 53.3,47.6,41.9$ and 37.3 (all NBE). FT-IR (ATR mode): $v\left(\mathrm{~cm}^{-1}\right)=2995(\mathrm{w}), 1672(\mathrm{~s})$, 1577 (s), 1426 (m), 1239 (w), 1048 (m), 739 (m).

Homopolymerization of M2: M2 (100 $\mathrm{mg}, 0.235 \mathrm{mmol})$ was dissolved in $5 \mathrm{~mL}$ of $\mathrm{CH}_{2} \mathrm{Cl}_{2}$ and treated with a solution of [Mo] $(3.0 \mathrm{mg}, 0.0042 \mathrm{mmol})$ in $1 \mathrm{~mL}$ of $\mathrm{CH}_{2} \mathrm{Cl}_{2}$. The resulting white cloudy reaction mixture was stirred for $2 \mathrm{~h}$ at room temperature. A solution of ferrocene carboxaldehyde (10-fold excess based on initiator) in $\mathrm{CH}_{2} \mathrm{Cl}_{2}$ was added and the mixture was then stirred for $1 \mathrm{~h}$ at room temperature. The polymer was filtered off, thoroughly washed with pentane and dried; yield: $90 \mathrm{mg}$ (90\%). Poly(M2): $M_{\mathrm{n} \text { (calc) }}=23600 \mathrm{~g} \mathrm{~mol}^{-1}, M_{\mathrm{n} \text { (found) }}=$ $24500 \mathrm{~g} \mathrm{~mol}^{-1}, \mathrm{PDI}=1.36 .{ }^{1} \mathrm{H} \mathrm{NMR}\left(\mathrm{CDCl}_{3}\right): \delta 5.83$ (broad s, $2 \mathrm{H}-\mathrm{C} \underline{\mathrm{H}}=\mathrm{C} \underline{\mathrm{H}}-), 5.17$ (broad s, $\left.2 \mathrm{H} \mathrm{CH}_{2}\right), 4.70\left(\right.$ broad s, $2 \mathrm{H} \mathrm{CH}_{2}$ ), 4.21 (broad d, $4 \mathrm{H} \mathrm{CH}_{2}$ ), 3.51 (broad s, $13 \mathrm{H} \mathrm{NBE}+\mathrm{NCH}_{3}$ ), 1.26 (broad s, $\left.3 \mathrm{H} \mathrm{CH}_{3}\right) \cdot{ }^{13} \mathrm{C} \mathrm{NMR}\left(\mathrm{CDCl}_{3}\right): \delta 171.3$ and 170.4 $(\mathrm{C}=\mathrm{O}), 132.7(-\mathrm{CH}=\mathrm{CH}-), 77.2(\mathrm{NBE}), 64.6,61.8,59.4\left(\mathrm{CH}_{2}\right)$, 55.1, 53.8 and $52.9\left(\mathrm{NCH}_{3}\right), 14.1\left(\mathrm{CH}_{3}\right)$. FT-IR (ATR mode): $v$ $\left(\mathrm{cm}^{-1}\right)=3428(\mathrm{w}), 2969(\mathrm{w}), 1726(\mathrm{~s}), 1427(\mathrm{~m}), 1181(\mathrm{w})$, $1018(\mathrm{~m}), 953(\mathrm{~m})$.

Synthesis of poly(M1-b-M2): A solution of [Mo] (2.4 mg, $0.0034 \mathrm{mmol}$ ) in $1 \mathrm{~mL}$ of $\mathrm{CH}_{2} \mathrm{Cl}_{2}$ was added to one of $\mathbf{M 1}$ (30.0 mg, $0.102 \mathrm{mmol}$ ) in $1 \mathrm{~mL}$ of $\mathrm{CH}_{2} \mathrm{Cl}_{2}$. The reaction mixture was stirred for $20 \mathrm{~min}$ and a small amount was withdrawn for GPC measurements. M2 (100 mg, $0.235 \mathrm{mmol})$ was dissolved in $2 \mathrm{~mL}$ of $\mathrm{CH}_{2} \mathrm{Cl}_{2}$ and this solution was added to the reaction mixture. The resulting white cloudy reaction mixture was stirred for another $90 \mathrm{~min}$. The polymerization was terminated with ferrocene carboxaldehyde (10-fold excess based on initiator) and the reaction was stirred for a further hour. The polymer was filtered off, thoroughly washed with pentane and dried; yield: $100 \mathrm{mg}(76 \%) . M_{\mathrm{n}}=44100 \mathrm{~g} \mathrm{~mol}^{-1}$, $M_{\mathrm{W}}=61100 \mathrm{~g} \mathrm{~mol}^{-1}$, PDI $=1.38 .{ }^{1} \mathrm{H} \mathrm{NMR}\left(\mathrm{CDCl}_{3}\right): \delta 8.40$, 7.92, 7.43, 7.33 (broad s, Py), 5.79 (broad s, - $\underline{\mathrm{CH}}=\mathrm{C} \underline{\mathrm{H}}-$ ), 5.17 (broad s, $\mathrm{CH}_{2}$ ), 4.70 (broad s, $\mathrm{CH}_{2}$ ), 4.21 (broad d, $\mathrm{CH}_{2}$ ), 3.51 (broad s, $\left.\mathrm{NBE}+\mathrm{NCH}_{3}\right), 1.87$ (broad, NHE), $1.27\left(\mathrm{CH}_{3}\right) .{ }^{13} \mathrm{C}$ NMR $\left(\mathrm{CDCl}_{3}\right): \delta 175.6(\mathrm{C}=\mathrm{O}), 171.3$ and $170.4(\mathrm{C}=\mathrm{O}), 154.8$, $148.9,137.8,134.6$ and 130.2 (all Py), 122.8 and 122.2 $(-\underline{\mathrm{CH}}=\underline{\mathrm{CH}}-), 77.0$ (NBE), 64.6, 61.6, $59.3\left(\mathrm{CH}_{2}\right), 52.8\left(\mathrm{NCH}_{3}\right)$, 22.3, $14.1\left(\mathrm{CH}_{3}\right)$. FT-IR (ATR mode): $v\left(\mathrm{~cm}^{-1}\right)=3404(\mathrm{w})$, 2937 (w), 1727 (s), 1679 (m), 1586 (m), 1467 (m), 1432 (w), 1375 (m), 1238 (w), 1184 (s), 1097 (w), 1018 (m), 954 (m), 749 (m).

Synthesis of poly(M1- $\boldsymbol{b}-\mathrm{M} 2)-\mathbf{R h}$ : $\left[\mathrm{Rh}(\mathrm{COD})_{2} \mathrm{Cl}\right]_{2}(8 \mathrm{mg})$ was dissolved in $\mathrm{CH}_{2} \mathrm{Cl}_{2}$. This solution was added dropwise to a suspension of poly(M1- $b$-M2) (100 mg) in $5 \mathrm{~mL}$ of $\mathrm{CH}_{2} \mathrm{Cl}_{2}$. The mixture was stirred for $10 \mathrm{~h}$ at room temperature; then the polymer was filtered off, thoroughly washed with pentane and dried; yield: $100 \mathrm{mg}$ (92\%). The Rh-content was determined by ICP-OES: $18 \mathrm{mg} \mathrm{Rh} / \mathrm{g}$ copolymer (12\% of the theoretical loading).

cmc determination of poly(M1-b-M2) and poly(M1-b-M2)$\mathbf{R h}$ : The cmc in water were determined by fluorescence spectroscopy [23] using 6-p-toluidene-2-naphthylsufonic acid $\left(10^{-6} \mathrm{M}\right)$ as the fluorescence probe. Polymer solutions were prepared in a concentration range from $1 \times 10^{-4}-1 \times 10^{-13} \mathrm{~mol}$ $\mathrm{L}^{-1}$. cmc of poly $(\mathbf{M 1}-b-\mathbf{M 2})=2.8 \times 10^{-6} \mathrm{~mol} \mathrm{~L}^{-1}$; $\mathrm{cmc}$ of $\operatorname{poly}(\mathbf{M 1}-b-\mathbf{M} 2)-\mathbf{R h}=2.2 \times 10^{-6} \mathrm{~mol} \mathrm{~L}^{-1}$.

Quantification of Rh: The amount of Rh bound to the block copolymers or leached into the products was determined by dissolving a $20.0 \mathrm{mg}$ amount of the polymer or the product mixture in aqua regia $(25 \mathrm{~mL})$. Rh was quantified by ICP-OES at $\lambda=343.489 \mathrm{~nm}$, measuring the background at $\lambda_{1}=343.410$ and $\lambda_{2}=343.600 \mathrm{~nm}$, respectively. A $1000 \mathrm{ppm}$ Rh standard ( $1 \mathrm{~N}$ $\mathrm{HNO}_{3}$, Merck, Germany) was used to prepare standards of 0 , $0.100,1.00$ and $10.00 \mathrm{ppm}$.

General procedure for hydroformylation: The reaction was carried out in a $300 \mathrm{~mL}$ Parr high-pressure reactor. The reactor was evacuated, flushed with argon and filled with the catalyst, water or toluene $(30 \mathrm{~mL})$, and 1-octene $(1.0 \mathrm{~g}, 0.0090 \mathrm{~mol})$, leading to a substrate to catalyst ratio of 5000:1. tert-Butylbenzene $(1.00 \mathrm{~mL})$ was added as internal standard. To purge the reactants, the mixture was pressurized with a 1:1 mixture of $\mathrm{CO}$ and $\mathrm{H}_{2}$ up to a pressure of 30 bar and then the pressure was released. Finally, the pressure was adjusted to 50 bar with the aid of a back pressure regulator. The autoclave was heated to $70{ }^{\circ} \mathrm{C}$ and kept at this temperature. Samples were taken every $30 \mathrm{~min}$. The isomeric 1-octenes and aldehydes were identified and quantified by their MS spectra as well as by their retention times using commercially available compounds as reference material. 
Recyclability studies with poly(M1-b-M2)-Rh: Hydroformylations were carried out as described above. For recycling, the product was extracted with diethyl ether $(4 \times 10 \mathrm{~mL})$. Fresh 1-octene $(1.0 \mathrm{~g}, 0.0090 \mathrm{~mol})$, and tert-butylbenzene $(1.0 \mathrm{~mL})$ were added to the aqueous, catalyst-containing phase and the reaction was run under the same conditions as before. The TONs in two consecutive cycles as determined by GC-MS were 4300 and 3900 , respectively.

\section{Supporting Information}

Supporting Information contains polymerization kinetics of M1 by the action of $\mathrm{Mo}\left(\mathrm{N}-2,6-\mathrm{Me}_{2}\right.$

$\left.\mathrm{C}_{6} \mathrm{H}_{3}\right)\left(\mathrm{CHCMe}_{2} \mathrm{Ph}\right)\left(\mathrm{OCMe}\left(\mathrm{CF}_{3}\right)_{2}\right)_{2}$, GPC-traces (DMF) of poly(M1) and poly(M1- $b-\mathbf{M} 2)$; cmc measurements for poly(M1- $b$-M2) and poly(M1- $b$-M2)-Rh in water; conversion of 1-octene, product formation, product distribution in the hydroformylation of 1-octene in toluene in the presence of $\mathbf{C 1}, \mathbf{C 1}$ and triphenylphosphite; $n$ :iso selectivities for catalysts poly(M1- $b$-M2)-Rh) and poly(M1-b-M2)-Rh with triphenylphosphite as a function of conversion.

\section{Supporting Information File 1}

Graphical representations of measurements.

[http://www.beilstein-journals.org/bjoc/content/

supplementary/1860-5397-6-28-S1.pdf]

\section{Acknowledgements}

Our work was supported by Clariant Germany, the Cluster of Excellence "Unifying Concepts in Catalysis" coordinated by the Technische Universität Berlin and the Federal Government of Germany and the Freistaat Sachsen. We are grateful to Dr. Wolfgang Geyer (UFZ, Leipzig) for his kind help with the fluorescence measurements as well as to A. Prager and Dr. U. Decker (IMO, Leipzig) for ICP-OES and NMR measurements.

\section{References}

1. Kotre, T.; Zarka, M. T.; Krause, J. O.; Buchmeiser, M. R.; Weberskirch, R.; Nuyken, O. Macromol. Symp. 2004, 217, 203-214. doi:10.1002/masy.200451316

2. Nuyken, O.; Persigehl, P.; Weberskirch, R. Macromol. Symp. 2002, 177, 163-173. doi:10.1002/1521-3900(200201)177:1<163::AID-MASY163>3.0.CO;2W

3. Nuyken, O.; Weberskirch, R.; Kotre, T.; Schoenfelder, D.; Wörndle, A. Polymers for micellar catalysis. In Polymeric Materials in Organic Synthesis and Catalysis; Buchmeiser, M. R., Ed.; Wiley-VCH: Weinheim, Germany, 2003; pp 277-304. doi:10.1002/3527601856.ch6

4. Nuyken, O.; Weberskirch, R.; Bortenschlager, M.; Schönfelder, D. Macromol. Symp. 2004, 215, 215-230. doi:10.1002/masy.200451118
5. Oehme, G. Micellar Systems. In Multiphase Homogeneous Catalysis, 1st ed.; Cornils, B.; Herrmann, W. A.; Horvath, I. T.; Leitner, W.; Mecking, S.; Olivier-Bourbigou, H.; Vogt, D., Eds.; Wiley-VCH: Weinheim, Germany, 2005; Vol. 1, pp 132-136.

6. Pawar, G.; Bantu, B.; Weckesser, J.; Blechert, S.; Wurst, K.; Buchmeiser, M. R. Dalton Trans. 2009, 9043-9051. doi:10.1039/b909180g

7. Weberskirch, R.; Preuschen, J.; Spiess, H. W.; Nuyken, O. Macromol. Chem. Phys. 2000, 201, 995-1007. doi:10.1002/1521-3935(20000601)201:10<995::AID-MACP995>3.0.CO ;2-T

8. Krause, J. O.; Zarka, M. T.; Anders, U.; Weberskirch, R.; Nuyken, O.; Buchmeiser, M. R. Angew. Chem. 2003, 115, 6147-6151. doi:10.1002/ange.200352637

9. Bantu, B.; Wurst, K.; Buchmeiser, M. R. J. Organomet. Chem. 2007, 692, 5272-5278. doi:10.1016/j.jorganchem.2007.08.009

10. Ungváry, F. Coord. Chem. Rev. 2007, 251, 2087-2102. doi:10.1016/j.ccr.2007.02.018

11. Holmberg, K. Eur. J. Org. Chem. 2007, 731-742. doi:10.1002/ejoc.20060074

12. Buchmeiser, M. R. Ring-Opening Metathesis Polymerization. In Handbook of Ring-Opening Polymerization, 1st ed.; Dubois, P.; Coulembier, O.; Raquez, J.-M., Eds.; Wiley-VCH: Weinheim, Germany, 2009; pp 197-225. doi:10.1002/9783527628407.ch8

13. Buchmeiser, M. R. Chem. Rev. 2000, 100, 1565-1604. doi:10.1021/cr990248a

14. Stubenrauch, K.; Moitzi, C.; Fritz, G.; Glatter, O.; Trimmel, G.; Stelzer, F. Macromolecules 2006, 39, 5865-5874. doi:10.1021/ma060451p

15. Buchmeiser, M. R.; Wurst, K. J. Am. Chem. Soc. 1999, 121, 11101-11107. doi:10.1021/ja991501r

16. Buchmeiser, M. R.; Lubbad, S.; Mayr, M.; Wurst, K. Inorg. Chim. Acta 2003, 345, 145-153. doi:10.1016/S0020-1693(02)01291-4

17. Trnka, T. M.; Grubbs, R. H. Acc. Chem. Res. 2001, 34, 18-29. doi:10.1021/ar000114

18. Grubbs, R. H. Angew. Chem. 2006, 118, 3845-3850. doi:10.1002/ange.200600680

19. Schrock, R. R. Polyhedron 1995, 14, 3177-3195. doi:10.1016/0277-5387(95)85005

20. Schrock, R. R. The Discovery and Development of High-Oxidation State Mo and W Imido Alkylidene Complexes for Alkene Metathesis. In Handbook of Metathesis, 1st ed.; Grubbs, R. H., Ed.; Wiley-VCH: Weinheim, Germany, 2003; Vol. 1, pp 8-32. doi:10.1002/9783527619481.ch3

21. Schrock, R. R. Chem. Commun. 2005, 2773-2777. doi:10.1039/b504541j

22. Oskam, J. H.; Fox, H. H.; Yap, K. B.; McConville, D. H.; O’Dell, R.; Lichtenstein, B. J.; Schrock, R. R. J. Organomet. Chem. 1993, 459, 185-198. doi:10.1016/0022-328X(93)86071-O

23. Ananthapadmanabhan, K. P.; Goddard, E. D.; Turro, N. J.; Kuo, P. L. Langmuir 1985, 1, 352-355. doi:10.1021/la00063a015

24. Dwars, T.; Haberland, J.; Grassert, I.; Oehme, G.; Kragl, U. J. Mol. Catal. A: Chem. 2001, 168, 81-86. doi:10.1016/S1381-1169(00)00542-2

25. Morawetz, H. Adv. Catal. 1969, 20, 341-371. doi:10.1016/S0360-0564(08)60276-X

26. Lipshutz, B. H.; Aguinaldo, G. T.; Ghorai, S.; Voigtritter, K. Org. Lett. 2008, 10, 1325-1328. doi:10.1021/ol800028x 
27. Mingotaud, A.-F.; Mingotaud, C.; Moussa, W.

J. Polym. Sci., Part A: Polym. Chem. 2008, 46, 2833-2844.

doi:10.1002/pola.22617

28. Oheme, G.; Grassert, I.; Paetzold, E.; Meisel, R.; Drexler, K.;

Fuhrmann, H. Coord. Chem. Rev. 1999, 185-186, 585-600.

doi:10.1016/S0010-8545(99)00012-0

29. Kotre, T.; Nuyken, O.; Weberskirch, R. Macromol. Rapid Commun.

2002, 23, 871-876.

doi:10.1002/1521-3927(20021001)23:15<871::AID-MARC871>3.0.CO; 2-G

30. Zarka, T. M.; Nuyken, O.; Weberskirch, R. Chem.-Eur. J. 2003, 9 , 3228-3234. doi:10.1002/chem.200304729

31. Kotre, T.; Nuyken, O.; Weberskirch, R. Macromol. Chem. Phys. 2004, 205, 1187-1195. doi:10.1002/macp.200300241

32. Schönfelder, D.; Nuyken, O.; Weberskirch, R. J. Organomet. Chem. 2005, 690, 4648-4655. doi:10.1016/j.jorganchem.2005.07.053

33. Schönfelder, D.; Fischer, K.; Schmidt, M.; Nuyken, O.; Weberskirch, R. Macromolecules 2005, 38, 254-262. doi:10.1021/ma048142r

34. Zarka, M. T.; Bortenschlager, M.; Wurst, K.; Nuyken, O.; Weberskirch, R. Organometallics 2004, 23, 4817-4820. doi:10.1021/om049495h

35. Bortenschlager, M.; Wittmann, A.; Schoellhorn, N.; Weberskirch, R.; Nuyken, O. Polym. Prepr. 2005, 46, 666-667.

36. Weissermel, K.; Arpe, H. J. Industrial Organic Chemistry; VCH: New York, 1993.

37. Sinner, F.; Buchmeiser, M. R.; Tessadri, R.; Mupa, M.; Wurst, K.; Bonn, G. K. J. Am. Chem. Soc. 1998, 120, 2790-2797. doi:10.1021/ja973495+

\section{License and Terms}

This is an Open Access article under the terms of the Creative Commons Attribution License (http://creativecommons.org/licenses/by/2.0), which permits unrestricted use, distribution, and reproduction in any medium, provided the original work is properly cited.

The license is subject to the Beilstein Journal of Organic Chemistry terms and conditions:

(http://www.beilstein-journals.org/bjoc)

The definitive version of this article is the electronic one which can be found at: doi:10.3762/bjoc. 6.28 